\title{
Non-Alcoholic Fatty Pancreatic Disease: A Review of Literature
}

\author{
Hassan Tariqa, b, Suresh Nayudu ${ }^{a}$, Sai Akella ${ }^{a}$, Mariela Glandt ${ }^{\mathrm{a}}$, \\ Sridhar Chilimuria
}

\begin{abstract}
There is an epidemic of obesity worldwide. The prevalence of obesity has doubled over the last three decades. Obesity, especially abdominal obesity is associated with insulin resistance that can lead to pancreatic steatosis and non-alcoholic fatty pancreatic disease (NAFPD). NAFPD describes a phenotype entity ranging from deposition of fat in the pancreas to pancreatic inflammation, and resultant fibrosis, which is similar to that of non-alcoholic fatty liver disease (NAFLD). NAFPD may represent a meaningful manifestation of metabolic syndrome. Pancreatic steatosis can be diagnosed on ultrasound, computed tomography (CT) scan or magnetic resonance imaging (MRI). In addition to a correlation between pancreatic steatosis and metabolic syndrome, pancreatic steatosis may lead to a worse outcome in pancreatitis and may be an etiological factor in pancreatic cancer, but we need further research to examine the associations, pathophysiology, and the impact of pancreatic steatosis and NAFPD on the human health.
\end{abstract}

Keywords: Non-alcoholic fatty pancreatic disease; Metabolic syndrome; Pancreatic steatosis

\section{Introduction}

Obesity is a chronic disease with multiple psychosocial dimensions that has an increasing prevalence among adults, adolescents and children. Considering the alarming increase in global epidemic of overweight and obese people, the term "globesity" was coined by the World Health Organization. As per the World Health Organization, there were about 200 million obese adults worldwide and another 18 million under-five children classified as overweight which has increased to more

Manuscript accepted for publication December 05, 2016

aBronx Lebanon Hospital Center, Department of Medicine, 1650 Selwyn Ave., Suite \#10C, Bronx, NY 10457, USA

${ }^{b}$ Corresponding Author: Hassan Tariq, Department of Medicine, Bronx Lebanon Hospital Center, 1650 Selwyn Ave., Suite \#10C, Bronx, NY 10457, USA. Email: HTARIQ@bronxleb.org

doi: https://doi.org/10.14740/gr731w than 300 million obese adults, with 115 million obese adults in the developing countries in 2000 [1]. In 2014, more than 1.9 billion adults, 18 years and older, were overweight. Of these over 600 million were obese. Overall, about $13 \%$ of the world's adult population (11\% of men and $15 \%$ of women) was obese in 2014. The worldwide prevalence of obesity has doubled between 1980 and 2014. In 2013, 42 million children under the age of 5 years were overweight or obese [2]. As per the data from National Health and Nutrition Examination Survey, the prevalence of obesity in United States is $34.9 \%$ [3]. There has been an increase in the mean body mass index (BMI) worldwide, with $36.9 \%$ of men and $38 \%$ of women estimated to have a BMI $\geq 25 \mathrm{~kg} / \mathrm{m}^{2}[4,5]$.

Obesity, especially abdominal obesity is associated with insulin resistance, leading to type 2 diabetes mellitus and the associated hyperinsulinemic state with hyperglycemia can lead to vascular endothelial dysfunction, dyslipidemia, and the development of atherosclerotic cardiovascular disease [6-9]. It also leads to the infiltration of fat in organs such as heart, kidneys, liver and pancreas [10].

Pancreatic steatosis was first described in 1933 by Oligvie, when he described the presence of pancreatic fat to be higher in obese individuals ( $17 \%$ vs. $9 \%$ ) as compared to lean individuals [11]. After this study, the next major description of fatty pancreas was done by Olsen, who evaluated 394 autopsies and found that the amount of pancreatic fat increases with age [12]. Stamm showed that that the most common pathologic finding in pancreas of individuals on autopsy was some degree of lipomatosis. He also showed that pancreatic fat increases with age and the presence of $>25 \%$ fat in the pancreas was associated with significantly increased risk of type 2 diabetes mellitus and severe generalized atherosclerosis [13].

Van Geenen et al hypothesized that obesity and the associated insulin resistance plays an important role in pancreatic adipocyte infiltration, causing pancreatic steatosis. Insulin resistance also leads to peripheral lipolysis, increasing the flux of fatty acids to the liver leading to non-alcoholic fatty liver disease (NAFLD). They implied that pancreatic steatosis precedes NAFLD and hence purposed that the term non-alcoholic fatty pancreatic disease (NAFPD) should be used [14].

\section{Nomenclature}

Oligvie coined the term "pancreatic lipomatosis" to describe 
Table 1. Common Nomenclature for Pancreatic Steatosis as Described by Smits and van Geenen [11]

\begin{tabular}{ll}
\hline Nomenclature & Definition \\
\hline $\begin{array}{l}\text { Pancreatic lipomatosis } \\
\text { Pancreatic steatosis }\end{array}$ & General terms that can be used for all forms of pancreatic fat accumulation \\
$\begin{array}{l}\text { Fatty pancreas } \\
\text { Lipomatous pseudohypertrophy }\end{array}$ & $\begin{array}{l}\text { An extreme variant of pancreatic fat accumulation when pancreas is enlarged (uniformly or focally), } \\
\text { the exocrine system is replaced by fat, and when no association can be found with obesity. }\end{array}$ \\
\hline Fatty replacement & $\begin{array}{l}\text { Damage of pancreatic acinar cells leading to their death which then results in their replacement in the } \\
\text { pancreas by adipocytes (usually irreversible). }\end{array}$ \\
\hline Fatty infiltration & $\begin{array}{l}\text { Pancreatic infiltration of adipocytes caused by obesity (possibly reversed by weight reduction and } \\
\text { appropriate medications). }\end{array}$ \\
\hline $\begin{array}{l}\text { Non-alcoholic fatty pancreas disease } \\
\text { Non-alcoholic fatty steatopancreatitis }\end{array}$ & $\begin{array}{l}\text { Pancreatic fat accumulation in association with obesity and metabolic syndrome. } \\
\text { Pancreatitis owing to pancreatic fat accumulation. }\end{array}$ \\
\hline
\end{tabular}

the excessive storage of fat in pancreatic tissue [11]. Many synonyms for accumulation of fat in pancreas have been used in the literature (Table 1) including pancreatic lipomatosis, pancreatic steatosis, fatty replacement, fatty infiltration, fatty pancreas, lipomatous pseudohypertrophy and NAFPD [11]. Smits and van Geenen purposed that pancreatic steatosis should be used to describe fat accumulation in pancreas, and fatty replacement should be reserved for cases in which damage to pancreatic acinar cells leads to their death and replacement by adipocytes. On the other hand, NAFPD should be reserved for pancreatic steatosis associated with obesity and metabolic syndrome [11].

\section{Pathophysiology}

NAFPD describes a phenotype entity ranging from deposition of fat in the pancreas to pancreatic inflammation, and resultant fibrosis which is similar to that of NAFLD, which describes a spectrum from hepatic steatosis through steatohepatitis to cirrhosis, and possible hepatocellular carcinoma. Given that the liver and pancreas have similar embryological origins, it is also plausible, as suggested for NAFLD, that obesity may lead to pancreatic cancer through pancreatic steatosis. This hypoth- esis is corroborated by studies implicating NAFPD as a risk factor in pancreatic adenocarcinoma [15].

Animal model studies have shown that offspring exposed to both maternal obesity and a post-weaning obesogenic diet have a more pronounced dysmetabolic and NAFPD phenotype [15]. These dysmetabolic offspring had a significant increase in body weight, pancreas tissue triglyceride content, increased pancreatic expression of the fibrogenic markers TGF- $\beta 1$ and collagen gene along with increases in a hypertensive phenotype [16].

In human studies, pancreatic fat content is closely associated with an increasing BMI, insulin resistance, metabolic syndrome, and hepatic fat content. Diabetes mellitus is independently associated with fatty pancreas, and vice versa. Subjects with fatty pancreas have an increased risk of diabetes compared with those without it [17]. Many previous studies have indicated that fatty infiltration of the pancreas may contribute to a loss of $\beta$-cell mass and function, which possibly leads to the development of diabetes. On the other hand, once diabetes develops, fatty replacement of damaged tissue may contribute to the exocrine pancreatic fat. Alternatively, the increased levels of malonyl coenzyme A caused by hyperglycemia may inhibit carnitine palmitoyltransferase 1 , leading to a decrease in mitochondrial $\beta$ oxidation and further stimulation of intra-

Table 2. Etiology of Pancreatic Steatosis [11, 18-29]

Increasing age
Obesity
Diabetes mellitus
Alcohol use in excess of $14 \mathrm{~g} /$ week
Hemochromatosis
Viral infections: hepatitis B, reovirus, human immunodeficiency virus infection and acquired immune
deficiency syndrome (HIV/AIDS)
Malnutrition states: kwashiorkor
Medication: gemcitabine, rosiglitazone
Congenital syndromes: cystic fibrosis, Shwachman-Diamond syndrome, Johanson-Blizzard syndrome,
heterozygous carboxyl-ester-lipase mutations


Table 3. Imaging Modalities for Diagnosis of Pancreatic Steatosis [11, 28-31]

\begin{tabular}{|c|c|c|}
\hline Imaging modality & Advantage & Disadvantage \\
\hline $\begin{array}{l}\text { Ultrasonography } \\
\text { (USG) }\end{array}$ & Widely available & $\begin{array}{l}\text { Pancreas may not be visible in obese patients. } \\
\text { Pancreatic fibrosis also appears hyperechogenic similar to fat deposition. } \\
\text { Pancreas echogenicity has been traditionally compared with liver echogenicity. } \\
\text { Liver is metabolically very active and its echogenicity exhibits high variance. }\end{array}$ \\
\hline $\begin{array}{l}\text { Endoscopic } \\
\text { ultrasound (EUS) }\end{array}$ & $\begin{array}{l}\text { The close proximity of the } \\
\text { ultrasound probe to the pancreas } \\
\text { results in superior spatial } \\
\text { resolution compared with CT } \\
\text { and MRI. }\end{array}$ & $\begin{array}{l}\text { Invasive procedure. } \\
\text { Requires sedation. } \\
\text { Carries risk of complications. }\end{array}$ \\
\hline $\begin{array}{l}\text { Computed } \\
\text { tomography }(\mathrm{CT})\end{array}$ & $\begin{array}{l}\text { Easily available. } \\
\text { Can be performed without } \\
\text { intravenous contrast for } \\
\text { diagnosis of pancreatic steatosis. }\end{array}$ & $\begin{array}{l}\text { No cut-off points for pancreatic steatosis on CT have been defined. } \\
\text { Exposure to radiation. } \\
\text { Mild degree of focal fatty replacement of pancreas cannot be diagnosed with CT } \\
\text { alone. }\end{array}$ \\
\hline
\end{tabular}

cellular triglyceride accumulation [17].

\section{Etiology}

As described earlier, factors and conditions associated with pancreatic steatosis (Table 2 [11, 18-29]) are age, obesity and diabetes mellitus. Other diseases associated include congenital syndromes such as cystic fibrosis [18-21], Shwachman-Diamond syndrome [22, 23], Johanson-Blizzard syndrome [24] and heterozygous carboxyl-ester-lipase mutations [25]. Pancreatic steatosis has also been associated with hemochromatosis [11], viral infections such as hepatitis B [26] and malnutrition states such as kwashiorkor [27].

\section{Imaging}

In the past, the diagnosis of pancreatic steatosis was made on in vivo autopsy specimens. With the advent of more advanced and sophisticated imaging modalities, pancreatic steatosis is most often found using these imaging techniques (Table 3) [11, 28-31].

Ultrasonography is the most widely and commonly used imaging technique. Lee et al diagnosed an increased echogenicity of pancreatic body over the kidney echogenicity during ultrasonography as fatty pancreas. They found that insulin resistance, visceral fat, triglyceride, and alanine aminotransferase (ALT) tended to increase with the degree of fat deposition in the pancreas. They found the presence of fatty pancreas along with fatty liver concurrently in many cases. They suggested that fatty pancreas might be the initial indicator of "ectopic fat deposition" and as an early marker of insulin resistance, which is a key element of fatty liver and/or metabolic syndrome [28]. Another study done by Al-Haddad et al, who used endoscopic ultrasound also found hepatic steatosis, alcohol use, and increased BMI as predictors of pancreatic steatosis, with hepatic steatosis being the strongest predictor with an odds ratio of nearly 14-fold [29]. Ultrasonography has some limitations considering that pancreas may not be well visualized in obese patients and pancreatic fibrosis also appears hyperechogenic. To avoid the later problem, kidneys or liver can be used as a reference point; a higher pancreatic echogenicity as compared to liver or kidney indicates pancreatic steatosis, while an echogenicity similar to retroperitoneal fat suggests highest amount of pancreatic fat deposition [11].

Computed tomography (CT) with or without contrast can also be used to evaluate for pancreatic steatosis. The density of steatotic pancreas is similar to adipose tissue on CT scan. The amount of pancreatic steatosis on $\mathrm{CT}$ can be measured using Hounsfield units, correlated to the spleen, a steatotic pancreas being hypodense on $\mathrm{CT}$ images with a negative Hounsfield unit as compared to the spleen [11].

The best imaging technique to evaluate for pancreatic steatosis is considered to be magnetic resonance imaging (MRI). There are various methods by which MRI can measure the pancreatic fat. The three most common methods are in phase-opposed phase, Dixon method and the spectral-spatial excitation techniques [30]. Wong et al used fat-water MRI and proton-magnetic resonance spectroscopy and found that the prevalence of pancreatic steatosis in Hong Kong Chinese volunteers was about $16 \%$. In this study central obesity, hypertriglyceridemia, and hyperferritinemia were found to be associated with fatty pancreas. They also suggested that people with fatty pancreas had an increased insulin resistance but no significant $\beta$-cell dysfunction [31].

\section{Clinical Consequences}

The metabolic syndrome, first described in 1988 by Reaven in the Banting Lecture, consists of central obesity, glucose intolerance or diabetes, hypertension and dyslipidemia [32]. Obesity also leads to the infiltration of fat in organs such as heart, kidneys, liver and pancreas [10]. Wu et al found that fatty pancreas is strongly associated with specific parameters 
of metabolic syndrome such as obesity, increased fasting blood glucose, elevated HbA1c and dyslipidemia [33]. It can be implied that NAFPD may represent a meaningful manifestation of metabolic syndrome.

The functional consequences of pancreatic steatosis remain largely unknown. Although fat accumulation in the pancreatic islets leads to a decreased insulin secretion, exocrine pancreatic insufficiency has not been well studied and only a few case reports have been reported in which patients with weight loss and massive steatorrhea were found to have severe pancreatic steatosis demonstrated on abdominal computed tomograms [34].

Smits and van Geenen hypothesized that increased amount of pancreatic fat associated with obesity is associated with a higher incidence and more severe episodes of acute pancreatitis due to imbalance of adipocytokines causing a general inflammatory state [11]. They also suggested that NAFPD causes pancreatic cancer, similar in pathophysiology to how NAFLD causes liver cancer [11].

\section{Conclusions}

In conclusion, pancreatic fat content is closely associated with an increasing BMI, insulin resistance, metabolic syndrome, and hepatic fat content. Various imaging modalities including ultrasonography, CT scan and MRI can be used to visualize pancreatic fat. The prevalence of pancreatic steatosis is increasing in parallel to obesity epidemic in the world. Pancreatic steatosis may lead to a worse outcome in pancreatitis and may be an etiological factor in pancreatic cancer, but we need further research to examine the associations, pathophysiology, and the impact of pancreatic steatosis and NAFPD on the human health.

\section{Disclosures}

None.

\section{Conflicts of Interest}

None of the authors have any financial conflicts of interest.

\section{References}

1. WHO. Controlling the global obesity epidemic, 2003. available from URL: http://www.who.int/nutrition/topics/obesity/en/.

2. WHO. Obesity and overweight, 2015. available from: URL: http://www.who.int/mediacentre/factsheets/fs311/ en/.

3. Ogden CL, Carroll MD, Kit BK, Flegal KM. Prevalence of childhood and adult obesity in the United States, 20112012. JAMA. 2014;311(8):806-814.

4. Ng M, Fleming T, Robinson M, Thomson B, Graetz N,
Margono C, Mullany EC, et al. Global, regional, and national prevalence of overweight and obesity in children and adults during 1980-2013: a systematic analysis for the Global Burden of Disease Study 2013. Lancet. 2014;384(9945):766-781.

5. Swinburn BA, Sacks G, Hall KD, McPherson K, Finegood DT, Moodie ML, Gortmaker SL. The global obesity pandemic: shaped by global drivers and local environments. Lancet. 2011;378(9793):804-814.

6. Reaven GM. Banting lecture 1988. Role of insulin resistance in human disease. Diabetes. 1988;37(12):15951607.

7. DeFronzo RA, Ferrannini E. Insulin resistance. A multifaceted syndrome responsible for NIDDM, obesity, hypertension, dyslipidemia, and atherosclerotic cardiovascular disease. Diabetes Care. 1991;14(3):173-194.

8. Lindsay RS, Howard BV. Cardiovascular risk associated with the metabolic syndrome. Curr Diab Rep. 2004;4(1):63-68.

9. Koh KK, Han SH, Quon MJ. Inflammatory markers and the metabolic syndrome: insights from therapeutic interventions. J Am Coll Cardiol. 2005;46(11):1978-1985.

10. Bonora E. The metabolic syndrome and cardiovascular disease. Ann Med. 2006;38(1):64-80.

11. Smits MM, van Geenen EJ. The clinical significance of pancreatic steatosis. Nat Rev Gastroenterol Hepatol. 2011;8(3):169-177.

12. Olsen TS. Lipomatosis of the pancreas in autopsy material and its relation to age and overweight. Acta Pathol Microbiol Scand A. 1978;86A(5):367-373.

13. Stamm BH. Incidence and diagnostic significance of minor pathologic changes in the adult pancreas at autopsy: a systematic study of 112 autopsies in patients without known pancreatic disease. Hum Pathol. 1984;15(7):677683.

14. van Geenen EJ, Smits MM, Schreuder TC, van der Peet DL, Bloemena E, Mulder CJ. Nonalcoholic fatty liver disease is related to nonalcoholic fatty pancreas disease. Pancreas. 2010;39(8):1185-1190.

15. Carter R, Mouralidarane A, Soeda J, Ray S, Pombo J, Saraswati R, Novelli M, et al. Non-alcoholic fatty pancreas disease pathogenesis: a role for developmental programming and altered circadian rhythms. PLoS One. 2014;9(3):e89505.

16. Oben JA, Patel T, Mouralidarane A, Samuelsson AM, Matthews P, Pombo J, Morgan M, et al. Maternal obesity programmes offspring development of non-alcoholic fatty pancreas disease. Biochem Biophys Res Commun. 2010;394(1):24-28.

17. Wang CY, Ou HY, Chen MF, Chang TC, Chang CJ. Enigmatic ectopic fat: prevalence of nonalcoholic fatty pancreas disease and its associated factors in a Chinese population. J Am Heart Assoc. 2014;3(1):e000297.

18. Tham RT, Heyerman HG, Falke TH, Zwinderman AH, Bloem JL, Bakker W, Lamers CB. Cystic fibrosis: MR imaging of the pancreas. Radiology. 1991;179(1):183186.

19. Murayama S, Robinson AE, Mulvihill DM, Goyco PG, Beckerman RC, Hines MR, Stallworth JM. MR im- 
aging of pancreas in cystic fibrosis. Pediatr Radiol. 1990;20(7):536-539.

20. Fiel SB, Friedman AC, Caroline DF, Radecki PD, Faerber $\mathrm{E}$, Grumbach K. Magnetic resonance imaging in young adults with cystic fibrosis. Chest. 1987;91(2):181-184.

21. Jones JS. Adult cystic fibrosis (mucoviscidosis). Fatty replacement of the pancreas in a woman aged 47 years. $\mathrm{Br}$ J Dis Chest. 1970;64(1):25-36.

22. Cubuk M, Arslan G, Ceken K, Ozkaynak C, Luyleci E. Schwachman-Diamond syndrome. A case report. Acta Radiol. 2000;41(6):627-628.

23. Lee JH, Bae SH, Yu JJ, Lee R, Yun YM, Song EY. A case of Shwachman-Diamond syndrome confirmed with genetic analysis in a Korean child. J Korean Med Sci. 2008;23(1):142-145.

24. Daentl DL, Frias JL, Gilbert EF, Opitz JM. The JohansonBlizzard syndrome: case report and autopsy findings. Am J Med Genet. 1979;3(2):129-135.

25. Raeder H, Haldorsen IS, Ersland L, Gruner R, Taxt T, Sovik O, Molven A, et al. Pancreatic lipomatosis is a structural marker in nondiabetic children with mutations in carboxyl-ester lipase. Diabetes. 2007;56(2):444-449.

26. Sasaki M, Nakanuma Y, Ando H. Lipomatous pseudohypertrophy of the pancreas in a patient with cirrhosis due to chronic hepatitis B. Pathol Int. 1998;48(7):566-568.

27. Diamond I, Vallbona C. Kwashiorkor in a North American white male. Pediatrics. 1960;25:248-257.
28. Lee JS, Kim SH, Jun DW, Han JH, Jang EC, Park JY, Son $\mathrm{BK}$, et al. Clinical implications of fatty pancreas: correlations between fatty pancreas and metabolic syndrome. World J Gastroenterol. 2009;15(15):1869-1875.

29. Al-Haddad M, Khashab M, Zyromski N, Pungpapong S, Wallace MB, Scolapio J, Woodward T, et al. Risk factors for hyperechogenic pancreas on endoscopic ultrasound: a case-control study. Pancreas. 2009;38(6):672-675.

30. Pezzilli R, Calculli L. Pancreatic steatosis: Is it related to either obesity or diabetes mellitus? World J Diabetes. 2014;5(4):415-419.

31. Wong VW, Wong GL, Yeung DK, Abrigo JM, Kong AP, Chan RS, Chim AM, et al. Fatty pancreas, insulin resistance, and beta-cell function: a population study using fatwater magnetic resonance imaging. Am J Gastroenterol. 2014;109(4):589-597.

32. Olufadi R, Byrne CD. Clinical and laboratory diagnosis of the metabolic syndrome. J Clin Pathol. 2008;61(6):697706.

33. Wu WC, Wang CY. Association between non-alcoholic fatty pancreatic disease (NAFPD) and the metabolic syndrome: case-control retrospective study. Cardiovasc Diabetol. 2013;12:77.

34. Lozano M, Navarro S, Perez-Ayuso R, Llach J, Ayuso C, Guevara MC, Ros E. Lipomatosis of the pancreas: an unusual cause of massive steatorrhea. Pancreas. 1988;3(5):580-582. 